\title{
Article
}

\section{Lean towards learning: connecting Lean Thinking and human resource management in UK higher education}

Thirkell, Emma and Ashman, Ian

Available at http://clok.uclan.ac.uk/11169/

Thirkell, Emma and Ashman, Ian (2014) Lean towards learning: connecting Lean Thinking and human resource management in UK higher education. International Journal of Human Resource Management, 25 (21). pp. 29572977. ISSN 0958-5192

It is advisable to refer to the publisher's version if you intend to cite from the work. http://dx.doi.org/10.1080/09585192.2014.948901

For more information about UCLan's research in this area go to http://www.uclan.ac.uk/researchgroups/ and search for <name of research Group>.

For information about Research generally at UCLan please go to http://www.uclan.ac.uk/research/

All outputs in CLoK are protected by Intellectual Property Rights law, including Copyright law. Copyright, IPR and Moral Rights for the works on this site are retained by the individual authors and/or other copyright owners. Terms and conditions for use of this material are defined in the policies page.

\section{CLoK}

Central Lancashire online Knowledge www.clok.uclan.ac.uk

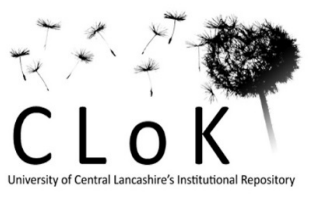




\section{Lean towards learning: connecting Lean Thinking and human resource management in UK higher education}

International Journal of Human Resource Management

E. Thirkell ${ }^{\mathrm{a}}$ and I. Ashman ${ }^{\mathrm{b}}$

${ }^{a}$ Institute for Research into Organisation, Work and Employment, Lancashire Business School, Preston, UK

${ }^{b}$ Institute for Research into Organisation, Work and Employment, Lancashire Business School, Preston, UK

Emma Thirkell, Lecturer in HRM, Lancashire Business School, Preston, UK, PR1 2HE Ian Ashman, Senior Lecturer in HRM, Lancashire Business School, Preston, UK, PR1 $2 \mathrm{HE}$ 


\title{
RESEARCH ARTICLE
}

\section{Lean towards learning: connecting Lean Thinking and human resource management in UK higher education}

\begin{abstract}
From its origins in the automotive industry, Lean Thinking is increasingly being seen as a solution to problems of efficiency and quality in other industries and sectors. In recent years attempts have been made to transfer Lean principles and practice to the higher education sector with indications of mixed consequences and debate over its suitability. This paper contributes to the debate by drawing evidence from thirty-four interviews conducted across two UK universities that have implemented Lean in some of their activities and we pay particular attention to the role of the HR function in facilitating its introduction. The findings suggest there are problems in understanding, communicating and transferring Lean Thinking in the higher education context; that, despite HR systems being vital facets of Lean, HR professionals are excluded from participation; and that as a consequence the depth and breadth of Lean application in the two institutions is very limited.
\end{abstract}

Keywords: academics; employee experiences; HRM; higher education; lean thinking

\section{Introduction}

Recent changes to university funding in the UK, occurring against a background of intensifying competition and financial austerity, have resulted in a dual challenge for higher education institutions (HEIs) of improving quality and reducing costs. At the same time, some have argued that students are adopting the traits of consumerism and that academic freedom is in retreat (Lynch and Baines 2004; Eagle and Brennan 2007; Voss et al. 2007; Gruber et al. 2010). As a consequence the HE sector appears increasingly to be employing quality concepts such as total quality management (TQM), business process reengineering (BPR) and, most recently, Lean. Evidence suggests that the results of such initiatives have been mixed (see, for example, Koch 2003; Quinn et al. 2009; O'Mahony and Garavan 2012).

Practitioners and scholars appear increasingly to be looking to the principles underpinning Lean in an attempt to resolve the economic and organizational pressures within HE as well as other parts of the public sector in the UK (Hines and Lethbridge 2010; Radnor and Bucci 2011). Of course, the origins of Lean rest in automotive manufacturing and so there are obvious concerns regarding the transferability of Lean production and management across economic sectors, industries, services and professions. Such concerns inform much of the current paper and in acknowledging the debate we often choose to use the phrase Lean Thinking to express the Lean concepts at the heart of our analysis. Womack and Jones (1996) introduced the notion of Lean Thinking to emphasise that Lean is more than systems and practices bound to a single industry, hence our adoption here. 
A review of research conducted since the publication of the seminal book The Machine that Changed the World (Womack et al. 1990) shows that the definition and understanding of Lean is changing to the point where it may no longer be recognisable, which is leading to confusion among scholars and practitioners (Holweg 2007). This is perhaps not surprising given the wide range of industries and sectors in which managers have tried to apply Lean. Arguably, the precise nature of the relationship between Lean and its context remains somewhat opaque and, essentially, an argument develops concerning a best practice versus a best fit approach to Lean (Cusumano 1992; Cooney 2002, Radnor et al. 2006; Radnor and Bucci 2007). Despite some theoretical and empirical progress, scholarly understanding of what Lean actually is and how it contributes to performance in organizational settings outside of manufacturing remains relatively underdeveloped, and there is a need to explore Lean in terms of 'fitness for purpose' especially within the public sector (Radnor and Osborne 2013).

Accordingly, a clearer examination of the impact of Lean on industries and sectors new to its uptake, accounting for the role of the HR function and the HR dimension of the application of Lean, is one of the most pressing research tasks - especially when considering that it is claimed that 'soft' facets, linked to people and culture, are often the cause of 'failed' Lean initiatives (Stewart et al. 2009; Emiliani 2011; Radnor and Osborne 2013). Evidence suggests that HR practices, such as training, performance management and involvement in decision making, especially when bundled together into an internally consistent HR system, can have a positive impact on the performance of professional industries through, for example, increase efficiency and effectiveness and higher service quality (Ichniowski et al. 1997; MacDuffie 1995; Pil and MacDuffie 1996; Lorenz and Valeyre 2005). Studies of Lean performance improvement also point to the importance of HR systems for achieving change with such aspects as skill acquisition, training, work design and leadership being considered particularly significant (Dankbaar 1997; Brockbank 1999; Green 2002). When this paucity of coherent theory that links Lean Thinking with HRM is coupled with problems of definition it is apparent that the present study contributes to a research field that is still in its infancy. The essential contribution of this paper lies in presenting experiences of implementation from a sector relatively new to Lean Thinking and subject to radical transition, through which employees' perceptions are explored from a HRM perspective, thereby advancing previous Lean performance improvement research and providing practitioners with a better understanding of the role of HRM.

Here we present findings from a multi-informant study conducted across two UK universities, both of which are going through transition as a result of recent changes within the HE sector. By focusing on employees' perceptions and experiences of Lean Thinking, including the reactions to HR practices, we answer the call to go beyond simple descriptions of how organisations are implementing Lean Thinking, that is characteristic of operations management accounts, and provide more depth to orthodox assessments of Lean Thinking (Bowen and Ostroff 2004; Kehoe and Wright 2013). Studies to date that have paid attention to employee perceptions tend to stem from manufacturing environments and generally focus on quality, efficiency, effectiveness, work intensification and process redesign (Garrahan and Stewart 1992; Bereggren 1993; Graham 1995; Rinehart et al. 1997; Stewart et al. 2009; Carter et al. 2011 and 2012).

The findings of our study indicate that the implementation of Lean Thinking in the UK higher education sector, coupled with a legitimate role for HR professionals, is 
potentially problematic. Weak conceptualisation, communication, patchy application and the exclusion of HR people and processes are all highlighted in the evidence presented and we conclude that, whilst it is to early to dismiss Lean as unsuitable for use in the UK higher education sector (or wider public sector), there are serious and, perhaps, unique factors that require further research attention both in the UK and elsewhere in the world.

Before progressing further we should perhaps declare that the position we have adopted for our exploration is to treat Lean thinking as an array of tools and techniques at the disposal of organisations that want to facilitate the implementation of process improvement and related change parameters, such as corporate culture. Lean, in our view is a repository from which methods can be drawn upon selectively, what has been referred to as 'Kaizen-type' by Radnor et al. (2006), rather than an all-encompassing philosophy in and of itself. Nevertheless, we recognise the influence and importance of alternative perspectives that range from treating Lean as a systemic solution to the problems of Twenty-first Century product and service delivery (Womack et al., 1990) to it being part of a capitalist agenda driven by the desire to reduce, subordinate and control labour (Carter et al., 2011; 2012; 2013).

We recognise particularly that the application of Lean in the public sector can be viewed as a social and economic ideology intended to enable new forms of employee subservience. Radnor et al. (2006), Radnor and Bucci $(2007 ; 2011)$ and Radnor and Osborne (2013) argue that Lean contributes to a broader managerial ideology in some organisations and that if human resource and other change management professionals carry out their roles correctly then Lean will be seen as a success. On the basis of the evidence gathered it is our belief that the two case study organisations in our study had no extant ideological agenda and simply wanted to improve processes to benefit stakeholders and facilitate a positive culture. That said, we acknowledge that we were not intent on hunting for ideological stances and so should any exist they may remain hidden. Ultimately, as we make clear later, while we recognise the importance of a variety of perspectives, we found no evidence, in intention or practice, that the reason for implementing Lean was to reduce, cheapen or extend control over employees

\section{Theoretical and Empirical Background}

\section{Lean and the problem of definition}

In order to study and evaluate something it must be tangible and so it is important that the concepts upon which it rests are clear. In other words, researchers have to know what they are looking for and are able to recognise it when they see it - with matters associated with Lean, however, conceptual clarity has become a problem. It is well known to those that are familiar with the notion of Lean that it derives from the International Motor Vehicle Program study, led by James P. Womack, that sought to facilitate a better understanding of the future of the automobile industry. Womack and his colleagues based the principles of Lean on the 'Toyota Production System' and asserted that:

'Lean production ... is 'lean' because it uses less of everything compared with mass production - half the human effort in the factory, 
half of the manufacturing space, half the investment in tools... half the engineering hours to develop a new product in half of the time.'(Womack et al 1990, p.13)

An examination of this definition suggests that there is a strong emphasis placed on the reduction of resources both in the factory and activities extending beyond the shop floor (Bruun and Mefford 2004). Womack et al. (1990) consider Lean to be a system that creates outputs using less of every input and although similar to the traditional massproduction system it offers increased choice for the end user, which it is argued signifies a paradigm shift (Price 1994; Perez 2005). This seems to suggest that Lean was once neatly defined, but that is now far from the truth - within today's literature on Lean the only agreement seems to be that there is no universally accepted definition (see, for instance, Lewis 2000; New 2007; Dahlgaard and Dahlgaard-Park 2006; Pettersen 2009). Shah and Ward (2007) claim that ambiguity has set in as a result of comparison with other terms such as the Toyota Production System, TQM and Just-in-Time and a conflagration of various change management concepts. Consequently, Shah and Ward (2007) suggest that Lean can be defined from either one of two perspectives: from a philosophical perspective that emphasises conceptualisation (or Lean Thinking) or from the practical perspective emphasizing integrated management systems.

Lean Thinking is often conceived as a combination of good operations management and effective people management that enables an organisation to implement process improvement and thus increase their efficiency and quality (Womack et al. 1990; Liker 2004; Womack and Jones 2005). Labour process theorists (for instance, Carter et al, 2011, 2012, 2013) argue that Lean is yet another initiative leading to the deskilling and work intensification, whereas proponents of Lean, whilst acknowledging that it can place additional demands on the workforce, claim that the outcome is a greater range of responsibilities and multi-skilling (Womack et al. 1990). It certainly seems to be the case that as Lean Thinking has found increasing favour in the UK public sector, the research undertaken there has been somewhat critical of its impact on employees in local government, healthcare and other public services (for instance, Radnor et al. 2006; Fillingham 2007; Kollberg et al. 2007; Radnor and Wally 2008; Esain et al. 2008; Radnor and Boaden 2008). This, among other issues, raises questions regarding the suitability of Lean principles and practice to contexts outside that in which it was originally conceived (Panizzolo 1998) and whether it can deliver the significant performance gains allegedly realised in manufacturing environments (Krafcik 1988; Womack et al. 1990).

\section{Transferring Lean Thinking across and between sectors}

The majority of research into Lean Thinking has been conducted within a manufacturing context and it is sometimes presumed that Lean is, therefore, only applicable to large volume industrial processes. Nevertheless, Womack et al. (1990, p.9) claimed from the start that the "fundamental ideas of lean production are universal - applicable anywhere by anyone" and there is evidence to show that Lean Thinking has been transferred from vehicle manufacturing to many other industries. That said a close review of the literature (See, for example, Abdullah \& Kennoy (1995) for electronics, Green (2002) and Jørgensen \& Emmitt (2008) for the construction industry, Bruce et al. (2004) for retail or Laureani et al. (2010) and Piercy \& Rich (2009) for call centres to name a few) does indicate broadly that transfer has taken place to predominantly manufacturing-like, 
high volume service processes (such as call centres found in banking and retail) with only limited evidence of application beyond environments with characteristics similar to manufacturing.

Nevertheless, most contemporary literature concludes that some characteristics of Lean can be transferred with discussion revolving around two different types of Lean implementation; full and 'kaizen-type' (Radnor et al. 2006, p.19). 'Full implementation' is the broad use of the tools associated with Lean and is consistent with the 'institutionalism' approach where the philosophy of Lean becomes all encompassing, especially with regard to organisational culture (Wright and McMahan 1992). The 'kaizen type', 'piecemeal' or 'non-embedded' approach (Radnor et al. 2006, p.19) refers to smaller scale implementations within specific processes on a one-off basis and is, perhaps, more likely in the public sector. This is because the long established bureaucracy of many state institutions, often embedded in complex legal, political and social accountability frameworks, creates an interconnectedness of systems that makes total system overhaul very difficult. Such a distinction between approaches detracts from the claims of universality and, given the stark differences between public service and private manufacturing contexts - and leaving aside the question as to whether it is appropriate to treat services such as healthcare or education as if they are tangible goods like automobiles (Radnor and Osborne 2013) - it is easy to envisage that there may be more challenges, problems and resistance than Womack and his like anticipate.

Various attempts to introduce Lean Thinking into the public sector in the UK have been researched but, significantly, there appears to be a lack of consensus over the extent and depth of Lean implementation and the measurement of outcomes with some recent reevaluations suggesting that earlier cited successes should be reconsidered (Emiliani, 2011; Radnor and Osborne, 2013).

\section{Lean Thinking and HRM: Integration and Implementation}

If a human resource system is understood to be a "set of distinct but interrelated activities, functions, and processes that are directed at attracting, developing, and maintaining a firm's human resources" (Lado and Wilson, 1994, p.701) then it is apparent that HRM will have a central role if Lean Thinking is to be implemented in a way that is consistent with an organisation's goals. Accordingly, employees' attitudes and behaviours act as key mediating variables through which HRM influences performance outcomes (Wright et al. 1994; Boxall 1996). Bowen and Ostroff (2004) argue that HR systems have a signalling function that allow employees to form a shared sense of the behaviours that are expected, supported and rewarded by management, thereby promoting constructive employee attitudes to Lean that are consistent with organisational goals. Furthermore, there is reason to assume HR involvement and visibility connected with the conveyance of consistent messages and organisational justice will also impact upon the successful delivery and maintenance of Lean principles (Tracey and Flinchbaugh 2006a, 2006b). Fundamentally, engagement with Lean Thinking will depend on how employees interpret the concept and imbue it with their own meaning and aspirations.

Moreover, transfer often depends on how employees interpret the meaning of Lean Thinking; the same can be said for HR systems whereby employees perceive and interpret HR practices subjectively, leading to attitudinal and, in turn, behavioural HR 
outcomes that are eventually related to performance outcomes at the organisational level (Nishii et al. 2008). There appears to be a consensus that a people orientated (or soft) approach toward HR strategy at various levels is a requirement of successful Lean applications, however, there is a lack of research encompassing the issue. Studies exploring the experiences of employees undergoing Lean Thinking are few and far between and those that do exist draw only from a manufacturing context. It is worth noting that there are clear parallels between the distinction made in Lean analyses of 'operations management' and 'people management' and the popular distinction in HRM between 'hard' and 'soft' approaches (Guest, 1987; Storey, 1987, 1992) although, interestingly, the hard/soft distinction has largely been ignored in the USA (Truss et al., 2003) where Lean has been applied to a greater extent than in the UK.

Oliver and Wilkinson (1992) argue that, alongside the inevitable 'hard' systems side that Lean incorporates, there needs to be a 'soft' human side focusing on culture change and personnel practices. They claim that the similarities in some aspects of Lean Thinking and HRM are quite striking, whilst noting that despite differences in philosophy and tradition they share an ethos in terms of placing high value on quality and being market driven and a focus on performance measurement. However, the 'kaizen-type' approach to Lean implementation, mentioned previously as being more prevalent in the public sector, is less likely to focus on softer cultural aspects (Radnor and Osborne 2013) and therefore less likely to embed HR practices and systems in implementation. Empirical evidence from the service sector indicates that employee perceptions of HR systems are linked to workplace behaviours such as organisational citizenship (Nishii et al. 2008) and employee service performance (Boxall et al. 2011; Aryee et al. 2012). These behaviours signify what Oliver and Wilkinson (1992) consider to be favourable worker attitudes - the foundation of change programmes like Lean.

While many obstacles confront organisations when implementing Lean Thinking the most common themes do appear to be HR related challenges comprising cultural as well as operational people management issues. Such factors have been shown to include a lack of management commitment and support (Achanga et al., 2005; Comm et al., 2008; Rahbeck et al., 2011), a lack of alignment between human resource strategy and the aims of Lean application (Tracey and Flinchbaugh 2006a), employee resistance (Carter et al., 2011; de Souza and Pidd, 2011), limited experience of leadership for change and indeed leadership more generally (Achanga et al. 2006), and inappropriate management behaviour (Ahrens 2006). Inadequate attention to HR issues is one facet but the quality of HR policy and practice, or lack thereof, can also cause problems in connection with change initiatives and training. HR shortcomings that can undermine the implementation of Lean Thinking include poor selection of change agents and improvement teams coupled with an insufficient appreciation of Lean principles (Ahrens 2006), a lack of engagement and 'buy-in' from teams and individuals towards improvement plans (Carter et al. 2011), 'silo thinking' (de Souza and Pidd 2011), failure to develop necessary skills and expertise (Achanga et al. 2005), poor communication and inadequate performance management systems that do not reward the adoption of Lean Thinking (Comm and Mathaisel 2008). 


\section{Lean and its application to higher education}

Evidence of the successful transfer of Lean Thinking to the public sphere is in relatively short supply and there are two possible reasons for this - although they are not mutually exclusive. The first is that Lean principles that may be effective in a private sector manufacturing context will not work for public sector service delivery. The second possible reason is that public organisations that are trying to implement Lean Thinking are not engaging the authentic Womack et al. version but some sort of partial or ersatz variety. Radnor and Osborne (2013) argue that this is the reason why UK public sector application of Lean principles is failing to achieve the desired outcomes, rather than any fundamental flaw in the Lean philosophy or its transferability. In a similar vein, Emiliani (2011) asserts that in US public sector organisations the preference has been for 'fake Lean', which leads him to argue that 'no Lean' is better than 'fake Lean'.

The prognosis for the transferability of Lean to the UK higher education context does not appear good. For instance, one of the more extensive studies of the application of Lean in the UK public sector, at Her Majesty's Revenue and Customs (Carter et al. 2012, p.121), concludes that "the introduction of Lean into HMRC is a backward step" and that only a tiny fraction of those interviewed "wanted Lean to continue in its present form". The outcome from a human resource management perspective, it is claimed, was increasing absenteeism and stress and deterioration in the quality of working life.

Much of the very limited assessment of the application of Lean Thinking to higher education has been carried out in the US, principally through the works of Emiliani (2004; 2007), Comm and Mathaisel (2005a,b; 2008) and Balzer (2010). In contrast, the tone here is predominantly prescriptive but the enthusiasm for the transferability of Lean is marked with the consensus being that Lean Thinking provides high quality education, at reduced costs, with efficient processes that instil pride, maximize value, and respect the long-term interests of students and employees.

The work that has been conducted in the UK on Lean in higher education is probably best described as guardedly positive, although the evidence base is relatively small and there is a significant dose of scepticism. For instance, Hines and Lethbridge (2008) claim that Lean Thinking is transferable to higher education institutions but then inject some caution with the qualification that universities have difficulty in coming to terms with the Lean concept and difficulty in defining their 'customer'. Radnor and Bucci (2011) suggest there are signs of a culture change taking place in the five UK universities of their study for the Association of Business Schools and judged that Lean was seen as successful in four of them - their assessment, however, is based on respondent perceptions of success alone rather than any measured outcomes.

Nevertheless, they also temper their optimism when acknowledging that numerous challenges face Lean implementation in UK higher education including; lack of accountability, ownership of change, and commitment from staff; inadequate resources and training; as well as resistance from academic managers.

The issue of resistance may develop from the unique nature and social tradition of universities. According to Ferlie and Geraghty (2005) universities are different from commercial and even other public organisations because they "produce knowledge rather than goods or service" (p. 428) and Chandler et al (2002) claim that any innovations in the UK higher education sector is likely to "raise awkward questions 
about life in English universities today which many senior academics and administrators would likely find uncomfortable" (p. 1065). There is a feeling in the UK that academic freedom is in retreat and that marketization and managerialism is creating a form of institution that suffers from a sense of organisational schizophrenia that has the potential to result in division and tensions between academic and non-academic or support staff. Indeed, Radnor and Bucci (2011) identified this issue, saying that academics need to learn to become customers of Lean processes.

Martin and Arokiam (2007), writing from an engineering management perspective, conclude that there is currently a "gap in knowledge that exists in order to deliver Lean in a holistic way and sustain it" in UK universities. They claim that, in respect to the diverse cultures apparent within such institutions, the development of a holistic model of Lean best practice that would apply across the whole higher education sector is 'impossible' to develop.

\section{Method}

\section{Research Design and data collection}

Evidence for the purpose of this research is drawn from two case study higher education institutions in the UK. The first is a long established 'traditional' university that we have given the pseudonym 'Old University' and the second is a 'modern' post 1992 university that we refer to as 'New University'. The challenge was to identify higher education institutions with on-going Lean programmes and so although the two institutions emerge from different historical contexts, which may influence the approach each adopts, this is not intended as a comparative study. Both institutions had been engaged with Lean Thinking and practice for similar lengths of time (between three and five years) and both claimed to adopt a 'soft approach' to implementation in the first instance at least. A summary of the principal contextual issues for each case study institution is provided in table 1 .

[insert table 1 near here]

To begin with a review and analysis of documentary evidence from both institutions (including such items as internal reports, minutes from meetings and training materials and feedback) was undertaken in order to provide context and, alongside the literature base, to enable the development of an interview schedule. Nevertheless, the schedule included open-ended questions to facilitate the collection of rich data and to allow any unanticipated issues to surface and be explored with respondents. The fieldwork for the study was undertaken May and December 2010. The data gathered was analysed using a thematic approach, initially via a manual reading and later facilitated by the use of QSR Nvivo9.

\section{Sampling}

The approach to sampling was entirely purposive in that respondents were identified and approached by an intermediary in each institution in accordance with their involvement with, and exposure to, Lean activities in their various roles. This in large part dictated the number of individuals accessed in each institution and the type of roles 
undertaken. For instance, the roll out of Lean at Old University encompassed a relatively large constituency but was restricted to administrative and support services. This was a consequence of the belief that Lean could not be applied or 'sold' to academic departments. By contrast in New University the coverage of Lean was broader, but in fact, impacted upon a smaller number employees. Thus, twenty two individuals in predominantly non-academic roles were interviewed from Old University and twelve interviews with individuals in predominantly academic roles were conducted at New University. In both organisations we spoke with senior managers, Lean facilitators, line managers and other employees experiencing the consequences of Lean Thinking.

\section{Findings}

In the first instance it must be acknowledged that the two case study universities adopted different approaches to both managing their resources and implementing Lean Thinking. This is especially true with regard to the training and skills development techniques employed. For instance, Old University required participants who were involved in the 'radical redesign' of processes touched by Lean to attend a 5-day 'blitz' by applying the Plan Do Check Act method (also known as the Deming Cycle) to all practices, thus drawing from the tradition of Total Quality Management. For each Lean Training Event, conducted by in-house Lean facilitators, a project team was identified and isolated from their normal work environment for the duration. That approach contrasts with New University where training in Lean techniques was optional for affected staff. The training that did take place generally involved away days to an automotive manufacturing plant where participants took part in building a car. The consequence of a voluntary approach was that Lean Thinking was being introduced into divisions being led by senior staff that had not necessarily been trained in Lean techniques. Nevertheless, despite the different approaches to implementation, the outcomes of the initiatives in the two universities were quite similar. Likewise, the ramifications for HRM and Lean implementation in the two institutions were also similar.

The data gathered for the present study covered a wide range of issues connected with the implementation of Lean Thinking in UK higher education institutions and so for the purposes of this paper an inductive approach was adopted for analysing the evidence and establishing the overarching themes for discussion. The eventual themes are prefigured in our assessment above of the theoretical background to the research, but also they arose from the issues prioritised by the respondents. The themes also reflect a number of important factors associated with various conceptualisations of HRM including: soft (cultural) versus hard (process) philosophies of HR; the rhetoric used in the selling and delivery of HR/Lean (Legge 1995); the strategic role for HR professionals (Storey 1992); and the application of 'one approach fits all' principles to a diverse workforce. Specifically the findings that follow cover: the manner in which Lean Thinking was communicated to employees and how they interpreted the concept; the theory and practice of human resource management and Lean implementation; and the limits of Lean Thinking in the higher education context. 


\section{Communicating and understanding Lean Thinking}

Evidence gathered from documentation and senior managers in the case study universities indicates that the desire in both was to introduce Lean Thinking as a means of establishing not only systems changes but also 'culture change'. Managers, in keeping with the notion of 'thinking', viewed the intention to move from inefficient bureaucracy to efficient administration as involving a shift in individual attitudes and behaviours as well as adapting policies and procedures. Culture change and so-called soft elements of Lean, often closely associated with the management of people, were advocated. A facilitator at Old University emphasized that Lean is about "a focus on customer service, quality and efficiency... We also want to embed Lean as how we do things around here; make it everyone's job to improve everything and for staff to take responsibility. A senior manager at New University gave expression to this in the following terms: "You need to create a [Lean] framework and you need to create the leadership that goes with it. You need to train the people; you need to operate it for people to get used to it and to see the benefits".

On the other hand, the employees that were the recipients of Lean implementation, whilst acknowledging that Lean raised issues such as personal respect and empowerment, tended to overlook the broader people perspective and view it as primarily being concerned with processes, tools and techniques (including visual management and metrics), waste reduction (including time) and general efficiency savings. An administrative manager at Old University saw Lean as "process reengineering, or mapping, using a set of tools to reduce so-called waste" whereas an academic at New University understood Lean to be about "measuring everything in order to improve processes." Thus, there was often a gap between what senior management understood Lean to be and what other employees understood.

Significantly, individuals in academic roles were able generally to provide definitions of Lean that aligned quite closely with Womack's original conceptualisation, perhaps because they had experience of Lean utilisation in the private sector or, in some instances, having taught on the subject, but could not (or would not) understand how it applied to their present occupation claiming that it was inappropriate for higher education and that it encroached on their autonomy and creativity. One academic suggested "Lean is a typical example of large organisations, as in HE, not trusting the Departments". Ironically, although maybe not surprisingly, non-academic staff often struggled to define Lean but possessed a much clearer understanding of the part it could play in their roles.

In part the multifarious interpretations of Lean Thinking in this higher education context arose from problematic communication. By all accounts the delivery of the Lean 'message' in both universities lacked consistency. This arose since delivery was generally left to institutional leaders and managers and so the clarity and quality of the message became a function of individual traits where, unsurprisingly, as a facilitator at Old University put it - "some are better than others". The content of the message varied because, as already discussed, there was uncertainty about what Lean Thinking actually constitutes (intra-variation) and differences between managers in their interpretation (inter-variation). The style by which the Lean message was delivered was also variable. The most obvious distinction was whether managers and leaders chose to 'tell' or 'sell' the Lean philosophy. Academics especially recognised the importance of 'selling' the 
philosophy to their colleagues in order to gain their support with a head of department at New University suggesting that "you have got to sell the idea to get people on board". 'Selling', however, may demand a level of knowledge and conviction regarding Lean Thinking that many did not appear to possess with academics admitting to either not applying Lean rigorously within their area (diluting implementation of Lean tools and techniques) or altering it according to what they saw as the real needs of their team. Ultimately this may well have a direct effect on what subordinates understand Lean to be.

Those in charge of facilitating Lean at both universities highlighted the importance of semantics in both communication and getting people to 'buy in' to the initiatives. It was also claimed that resistance could develop if the terminology was not adapted to take account of the ideals of higher education. Furthermore, and somewhat paradoxically, even academics that appeared comfortable with commercialism in universities objected to Lean. The same head of department at New University said, "I know that my group will be a little bit cynical about what Lean means, but if I don't use the word 'Lean' and use other [business] terms then they will be quite happy with it". Indeed, other respondents tended to view support from colleagues for Lean initiatives as being stronger where communication did not involve directly the use of the term 'Lean' because they seemed to believe that Lean was only appropriate in the environment in which it was conceived. Evidently Lean Thinking has an image problem in our case study universities as it does in much of the public sector.

\section{The human resource function and Lean implementation}

In both universities there were signs that Lean initiatives were changing (sometimes significantly) the ways in which employees carried out their work and so it was surprising to many respondents that the HR function was not involved in the implementation of any aspects of the introduction of Lean in either institution. Where roles had been altered as a consequence of Lean the incumbents expressed the view that there was certainly a need for their HR department to be participating in the events taking place because at Old University, for example, there was disagreement regarding interpretations of how Lean Thinking fitted with an existing public sector framework agreement. The experience of a Lean facilitator helps to illustrate the issue: "When approaching academics it was very much all about the public sector framework agreement. [The academic said] 'In my role it does not say that I must apply continuous improvement to my post. So, I'm not prepared to go with this any further"'. The response was always to retreat to relatively fixed positions whereas the optimal position would be to have HR specialists resolve any inconsistencies in advance.

However, despite their surprise and acknowledgement of the potential importance of HR issues, the evidence from respondents at both universities indicates that there were two related reasons for the absence of their respective HR functions in the implementation of Lean Thinking. First, many HR policies and practices, such as training and development (independent of Lean events), performance management and job evaluation, were viewed by facilitators as barriers or, at least, hindrances to Lean implementation. Ironically, there were widely held views that those very same systems were themselves in need of streamlining but the preferred option appeared to be to bypass rather than confront HR process limitations. An academic at New University suggested the rewards system (among others) does need changing to facilitate Lean but 
"a lot of the [HR] elements related to Lean are stifled by University processes so, for example, in the case of rewards there is a Performance Review Process where the reward is for enacting the process rather than delivering performance...I think that goes against the fact that the University [as a whole] hasn't bought into Lean. It is still the Business School and to a certain extent Social Sciences." This was supported by a senior manager at New University who suggested the rewards system (among others) does need changing to facilitate Lean but "we operate in a HR system within the University [as a whole] with some conducive HR processes and some which are not so it is important for us to engage with the rest of the University to move us all forward in the same direction." The decisions to avoid HR systems may stem from the second reason for the absence HR function participation - the perceived lack of ability among each university's HR professionals a senior manager at Old University claiming "HR are incapable of implementing Lean". In both cases senior and other managers intimated that their HR department colleagues failed to adopt strategic roles, were unable to accommodate new ways of thinking and were 'incapable' of applying Lean Thinking.

The perception of the HR function in both universities was somewhat negative in relation to Lean implementation at least. Nevertheless, there is some indication that responsibility for the absence of HR considerations from the implementation of Lean may not lay entirely at the door of the HR departments. For instance, one manager at Old University justified distrust by saying' "HR is probably the department that needs Lean Thinking the most" - which is to miss the point rather. Here is evidence of the 'kaizen-type' implementation of Lean that Radnor and Osborne (2013) identified as being one off measures that are not embedded in the fabric of the organisation and the complete reliance of Old University on Lean training events to try to establish pervasive Lean Thinking reinforces that evidence.

At Old University there also appeared to be a quasi-political dimension to the exclusion of the HR function, linked to our earlier discussion of communicating Lean, with a senior academic there saying, "If HR is the driver it is easy for staff to see the agenda as being about staffing. If something called 'Business Improvements' is the driver then it's easier for staff to see what this is about - improving the business". Some academic staff at New University echoed this type of assessment; the implication being that if the HR function is involved then Lean, rightly or wrongly, will be associated instantly with staffing upheaval and reductions. The rhetoric of 'business improvement' over concern for changes to work design and employment conditions (real or imagined) is a central issue here.

Regardless of the rhetoric Lean Thinking and HRM appear to be tied like a Gordian Knot and the inextricability of their relationship may be more pronounced in the public sector where there are layers of accountability that are rarely found in the private sector. An academic from New University, whose role oversaw commercial activities, remarked that: "The problem with an academic institution is that you have an awful lot of bureaucracy, you have an awful lot of quality assurance and you have got it all wrapped up in this HR blanket that sometime protects employees and stops us being able to do what we need to do". Although we found no direct evidence to support the notion that HR 'bureaucracy' was responsible for hampering the introduction of Lean it was a view that was shared elsewhere, as the following statement from a head of school at Old University demonstrates. "In the private sector I can really see [the HR department being strategic] and working well. You have the ability to fire people and it 
is baffling that the public sector does not have that ability. The issue with it is - if I went to Lean our office and discover that I have two too many staff - could I make them redundant? I could, maybe! But it would be a seriously hard process".

Such a view is in danger of perpetuating the widely held (but in theory mistaken) belief that Lean initiatives inevitably result in downsizing although, for the record, neither university had made redundancies as part of their application of Lean, or otherwise, at the time of data collection. Of course, correlating the application of Lean Thinking with job losses is extremely tenuous under any circumstances. Lean facilitates change but it always comes about as a consequence of change so demonstrating cause and effect is impossible in practice

The pressing problem at each university appeared to be an inability to redesign work characteristics, and to move people about between jobs as a consequence of the perceived restrictions of HR policy and practice. A senior manager in an academic department at New University acknowledged the need to challenge this issue: "How do we change our HR practices? That's a longer term thing for us because we have started it in this case from a school in a university; we operate in a HR system within the university [as a whole]. Some of them are conducive, some of them are not and in that process it is important for us to engage with the rest of the University to move us all forward in the same direction".

Ultimately, the evidence indicates that, in common with Lean itself, the HR function has an image problem. Senior managers in both institutions acknowledged that human resource policies, practices and professionals are essential aspects of their vision to establish 'culture change' through the application of Lean Thinking and they expressed ambitions to involve their HR departments in future. They were aware that Lean should not be viewed solely from a simple 'process reduction' point of view, but should be seen as a holistic and integrated approach. However, there was scepticism across the board regarding the capability of HR professionals to carry Lean through and some respondents went as far as to say they would consider it detrimental if the HR function was to become involved. Interestingly, and perhaps worryingly from an HRM perspective, respondents presented no prima facie evidence to support their impression, rather it was based on a pervasive sense that HR employees are simply not up to the job. This reflects a widely held view of the profession across sectors that has persisted for some years (Storey 2007).

\section{Limits to Lean in a higher education context}

In both case study universities Lean had limited breadth of application, in terms of coverage across functions and activities, and limited depth of application, in terms of demonstrating change to working practices and measurable outcomes.

\section{Breadth of application}

With regard to breadth of application, we noted earlier that Old University confined its implementation of Lean Thinking to non-academic departments and even its coverage of those was partial - the most notable omission being the HR function. The cited reason for excluding academic departments was that lecturing and research staff would not tolerate the introduction of Lean, and the circumstances surrounding the HR department 
have already been discussed. The obvious question that this raises, but for which no convincing justification is forthcoming, is - how is it defensible to introduce Lean Thinking into an organisation where the core 'business', and the people management systems that surround it, is left untouched?

At New University academic departments were, in theory, included in their Lean initiatives but, in practice, and despite the claim of Emiliani (2004) that Lean can affect frontline education via improved lectures, assignment content, management of student time, and overall student satisfaction, it was exclusively administrative processes that fell within its scope. The reasons for this reflect the evaluations of the researchers discussed in our coverage of the empirical background to Lean in higher education with our respondents citing a number of predictable explanations for the omission of academic delivery. The general view was that the intangible nature of delivering a 'knowledge service', the absence of educational outputs that are legitimately under the control of academics, and the personality characteristics of a 'typical' academic, all militate against the application of Lean Thinking in the teaching realm. In addition, one academic from New University pointed out that faults or issues in the frontline delivery of education may not become apparent for some considerable time and only become manifest in say, student failure rates, by which time it is too late and the root problem may no longer be relevant. Another academic from New University objected to predetermined models of working saying that academics are "people who are attracted to the notion of being autonomous teachers and researchers and bring with them several models of working".

Unsurprisingly then, the main resistance to Lean Thinking came from academics. This fact was singled out by many, including the academics, as the most significant barrier to Lean implementation. They appeared to understand the rationale behind the introduction of Lean Thinking to their institutions but their reluctance to change their working practices was indicative of their ambivalence. An academic at New University suggested the reason why academics are more critical of Lean is "because they are academics and that is what they are paid to do and also because it is a very emotive thing, teaching, it is about showing your personality and getting ideas across and you engaging with people so the idea of 'Leaning' that process is alien to a lot of the academics."

Another academic suggested they did not tolerate Lean due to its over emphasis on what they believed to be measurements "I've no problem with Lean but what I do have a problem with the fact that not everything is measurable and Lean is just obsessed with having a task measurement so some of the measurements that are sitting there are completely made up, which is counterproductive." At New University there is evidence that the approach to Lean training, which we can recall centred on a visit to an automotive plant, was alienating staff. The head of an academic division said; "I don't think [academics] particularly liked the [training] regime - academics felt that academia doesn't work like that. So if you were trying to sell Lean then maybe we should have adapted the training to how it would work in an academic institution, because we are not in a car plant and it is very different to how we work". This obvious disjuncture between the content of Lean training and the context of its application is difficult to comprehend, and we can only speculate as to whether the absence of input from the HR function contributed to the situation. 
Resistance also became manifest in more passive forms. For instance, there was evidence across the board that told of individuals informing their senior managers that they were using Lean principles (as they understood them) when, in practice, they knew they were not (most likely resorting to previous tried and tested methods). The same head of division at New University, cited earlier, was candid in admitting, "I will say to [the senior management sponsor] that I am doing Lean and implementing it in my division. Am I really doing that? No! Not at all! But I am seen to be implementing it and that's the main thing".

Beyond issues of resistance there were also problems of coherence and coordination in both case study institutions. Many elements of what a university delivers draw on participation from a variety of functions across the institution and, on occasions, Lean Thinking was viewed as counterproductive when administrative staff found that they were struggling to adopt Lean principles and practice in their own work environment and then have to abandon them when operating outside of it. A member of the administrative staff at New University suggested "the difficulty in the university structure is that the administrators may know about [Lean] but they are managed by the university, they are managed by college management teams so it is not the same. None of the administrative teams really own any of the Lean projects but they may be part of a team....and while the university is very positive about it and supportive about it and is keen to integrate it into various parts of their work, but at the same time there is inertia in the systems and not everybody knows how to deal with some of the process changes that are required." The most apparent examples of this were referred to earlier - where HR systems impinge upon the application of Lean.

\section{Depth of application}

Difficulties and inconsistencies in applying process changes led many interviewees to claim that change was superficial and limited, whereby implementation was believed to have had little effect on working practices, individual roles or organisational efficiency. In common with other studies cited earlier we cannot point to measured consequences to substantiate this view and likewise have to rely on the perceptions of those affected by Lean. Nevertheless, given that some outcomes, such as culture change, are very difficult if not impossible to quantify and others, such as process redesign, are experienced directly by respondents their opinions are important and will inform their future engagement with Lean initiatives. Many argued that what they saw as inherent public sector characteristics, such as hierarchy, bureaucracy and a silo mentality, made it difficult, if not impossible, to embed Lean in their institutions. An academic highlighted the problems with silo mentality within New University "while there are people working in a marketing division and others working in a finance division you never speak to other lecturers, you know, and there is a real cultural divide between the support staff and the lecturers. Lecturers don't communicate across divisions and lecturers don't communicate to support staff and vice versa; it's all very isolated and it doesn't feel like we are all working together." The existence of a blame culture was mentioned as an impediment to change at both case universities with the implication that when colleagues were approached about applying Lean Thinking to their role they took it as personal criticism and put up their defences.

Importantly, and an issue presumably unique to universities, 'academic freedom' was regarded as the most significant barrier to Lean implementation. Academics viewed 
their professional autonomy as the sine qua non of their occupation - the principle reason why they became lecturers and researchers. Any perceived attack on that freedom went to the heart of their raison d'etre. This fundamental objection to Lean was accompanied by a more prosaic concern regarding the likelihood of work intensification, although there was no apparent evidence that frontline education roles had been intensified.

Despite the general cynicism regarding the effectiveness of Lean Thinking and its application there was acknowledgement that some operational changes had occurred although questions remained over whether they represented genuine improvements and whether they were sustainable. With regard to the stated aspiration of achieving culture change the equivocation of a senior manager at New University is, perhaps, most prescient: "Operationally there will be changes, and changes have already occurred these are slower, transitional changes. In terms of the culture, I don't think that will ever change. You have got too many people who have been here for a very long time; they are academics! The number embracing it will gain momentum and maybe you will get cultural change, but culture doesn't shift overnight. You are talking 5 to 10 years before you see any real effects."

\section{Discussion and Conclusions}

This article argues, given the evidence from two case studies, that within the higher education context Lean thinking can suffer from the absence of clarity and engagement in relation to academics. Also, at least in part as a consequence of the exclusion of HR professionals from the implementation stage, the selection and application of Lean tools and techniques is managed poorly. As a result of our evaluation we put forward a number of propositions for further consideration and indicate how future exploration may enhance our understanding of the relationship between Lean thinking and HRM.

The findings from our study have a good deal in common with those of Hines and Lethbridge (2008) and Radnor and Bucci (2011) although, arguably, they paint a less optimistic picture for the application of Lean Thinking in the UK higher education sector. The prognosis for the role of HR professionals in the delivery of Lean is also somewhat negative. Nevertheless, in contrast with some researchers, such as Carter and his colleagues (Carter et al 2012), we think it is still too early to judge with any conviction the efficacy of Lean Thinking in higher education or similar areas of public service. In the first instance, it is evident that in the case studies we present there is an absence of clarity when it comes to a shared understanding of what Lean Thinking is, understanding what parts of the organisation it is appropriate to apply it to, and establishing the most effective mechanisms through which to embed it. The heterogeneity of UK universities means that it is unlikely that a definitive notion of Lean will apply across the board - Womack's (1990) claims of universality are idealistic - and adaptations to models will have to be made given different inputs, outputs and environments. Consequently, our first proposition infers a need for research and theory building to consider how the philosophy of Lean thinking can be maintained whilst practice is adapted to specific contextual conditions.

Proposition 1: The adoption and implementation of Lean Thinking across the UK higher education sector is unlikely to succeed until greater conceptual clarity is attained and more account taken of particular situation/context. 
In the second instance, it is apparent that the absence of human resource professional involvement is detrimental to achieving the strategic aims of Lean (in these cases efficiency improvements and cultural change). Our data does not allow the apportioning of blame for this situation and it would be inappropriate to do so but we can say with some confidence that all parties, be they sponsors, managers, facilitators or HR professionals, are responsible for ensuring that pervasive HR systems are integrated into Lean implementation and that expert HR advice is sought and provided. Some HR processes are more or less stand alone and so, for instance, Old University was able to include payroll under the aegis of its Lean programme but the line of least resistance in the case of systems, such as performance management, job design and evaluation, and workforce planning, that are embedded in core 'business' activities was adopted. The delivery of Lean training events was considered to be less than ideal in both case study institutions and the requirement for improved strategic, coherent and relevant (to the participants, at least) training was evident. It is this aspect of Lean implementation that may offer the best opportunity for HR professionals to contribute to the development of Lean application, to demonstrate their importance to Lean processes and to ensure the integration of all relevant HR systems into the venture. Our second proposition reflects our view that the apparent separation of HRM and Lean thinking is harmful to HR professionals and the organisations that are failing to make best use of them.

Proposition 2: The exclusion of relevant HR professionals from the implementation of Lean thinking will be detrimental to the success of such initiatives.

There would seem to be obvious overtones of the distinction between soft and hard HRM in the evidence we present and it may be appropriate for future research to focus more directly on the suitability of Lean Thinking to the principles and practice of soft HRM and also to explore the ways in which a soft Lean/HR rhetoric may be being used to facilitate hard Lean/HR outcomes. Concerns about the use of soft rhetoric to promote HR techniques, such as performance management, employee involvement and employment flexibility as democratising interventions, whilst being used to effect hard consequences, such as work intensification, tightened managerial control and redundancy, apply equally to the rhetoric forming behind Lean thinking. We, therefore, propose that such evident parallels are explored where HRM meets Lean.

Proposition 3: More attention should be paid, regarding theory and practice, to the related rhetoric of Lean and HR processes, techniques and outcomes.

The issues of the lack of conceptual clarity and HR involvement, described above, will not be unique to the higher education context, but a third issue, the intransigence/relative autonomy of academic employees, may be, so we posit questions for further consideration. Are academics, undertaking the task of knowledge creation and acquisition, a breed apart and for whom the 'imposition' of Lean Thinking would undermine their activities and raison d'etre? The evidence presented here suggests that the answer is - yes. The attitudes of academics in our two universities and the difficulty associated with the judgement of their outputs represent the most serious challenges to implementing Lean in higher education - perhaps the issue is intractable. On the other hand, this may be a trait that is peculiar to UK academics. Evidence from North America, provided by Emiliani (2004; 2007), Comm and Mathaisel (2005a,b; 2008) and Balzer (2010), seems to indicate a different attitude and more evidence from other parts 
of the world will be enlightening. The potential for cooperation or resistance within particular occupational groups adds a demanding complexity to the analysis of the relationship between HRM and Lean. Our final proposition reflects our evidence that professional occupations, in particular, are likely to resist Lean implementation.

Proposition 4: Strength of professional identity (in this instance, of UK academics) is inversely related to the willingness to engage positively with Lean Thinking.

There is no reason to suspect that the experiences in our case study institutions are atypical, but there is not enough evidence from research in higher education, or the wider public sector, to begin to generalise about the suitability of Lean in such contexts. There appears to be even less understanding of the impact of Lean across international boundaries and cultures, so given the increasing popularity of Lean and the claims being made on its behalf, the work to establish its legitimacy has barely begun. Similarly, consideration of the organisational HR function in the development and implementation of Lean initiatives across all economic sectors needs urgent attention - not least from the HR profession itself.

\section{References}

Abdullah, Syed R. S. and Keenoy, T. (1995) 'Japanese Managerial Practices in the Malaysian Electronics Industry: Two Case Studies', Journal of Management Studies, 32 (6): 747-766.

Achanga, P., Shehab, E., Roy, R. and Nelder, G. (2005), 'Lean manufacturing to improve cost-effectiveness of SMEs', in Seventh International Conference on Stimulating Manufacturing Excellence in Small and Medium Enterprises, Glasgow, University of Strathclyde.

Achanga, P., Shehab, E., Roy, R. and Nelder, G. (2006), 'Critical success factors for lean implementation within SMEs', Journal of Manufacturing Technology Management, 17: 460-471.

Ahrens, T. (2006) Lean production: Successful implementation of organizational change in operations instead of short term cost reduction efforts, Lean Alliance, available at http://www.lean-alliance.com/en/images/pdf/la_lean_survey.pdf [Last accessed 15th July 2014].

Aryee, S., Walumba, F.O., Seidu, E.Y.M., and Otaye, L.E. (2012) 'Impact of HighPerformance Work Systems on Individual- and Branch-Level Performance: Test of a Multilevel Model of Intermediate Linkages', Journal of Applied Psychology, 97: 287-300.

Balzer, W.K. (2010) Lean Higher Education: Increasing the Value and Performance of University Processes, New York NY: Productivity Press.

Berggren, C. (1993) Alternatives Lean Production. Work in the Swedish Auto Industry, second edition, Ithaca NY: Cornell University Press.

Bowen, D.E. and Ostroff, C. (2004) 'Understanding HRM-Firm Performance Linkages: The Role of the 'Strength' of the HRM System', Academy of Management Review, 29: 203-221.

Boxall, P. (1996) 'The Strategic HRM Debate and the Resource-Based View of the Firm', Human Resource Management Journal, 6: 59-75.

Boxall, P., Ang, S.H. and Bartram, T. (2011), ' Analyzing the 'Black Box' of HRM: Uncovering HR Goals, Mediators, and Outcomes in a Standardized Service Environment', Journal of Management Studies, 48: 1504-1532. 
Brockbank, W. (1999), 'If HR were really strategically proactive: Present and future directions in HR's contribution to competitive advantage', Human Resource Management, 38: 337-352.

Bruce, M., Daly, L. and Towers, N. (2004) 'Lean or agile: a solution for supply chain management in the textiles and clothing industry', International Journal of Operations \& Production Management, 24(2): 151-170.

Bruun, P., and Mefford, R. N. (2004) 'Lean production and the Internet', International Journal of Production Economics, 89: 247-260.

Carter, B., Danford, A., Howcroft, D., Richardson, H., Smith, A. and Taylor, P. (2011) 'Lean and mean in the civil service: the case of processing in HMRC', Public Money and Management, 31: 115-122.

Carter, B., Danford, A., Howcroft, D., Richardson, H., Smith, A. and Taylor, P. (2012) 'Lean and 'Nothing gets done and no one knows why': PCS and workplace control of Lean in HM Revenue and Customs', Industrial Relations Journal, 45: 416-432.

Carter, B., Danford, A., Howcroft, D., Richardson, H., Smith, A. and Taylor P. (2013) 'Stressed out of my box': Workers' experience of occupational ill-health in lean clerical work', Work, Employment and Society, 27(5): 747-767.

Chandler, J., Barry, J. and Clark, H. (2002) 'Stressing Academe: The Wear and Tear of the New Public Management', Human Relations, 55: 1051-1069.

Comm, C. and Mathaisel, D. (2005a) 'A case study in applying lean sustainability concepts to universities', International Journal of Sustainability in Higher Education, 6: 134-146.

Comm, C. and Mathaisel, D. (2005b) 'An exploratory study of best Lean sustainability practices in higher education', Quality Assurance in Education, 13: 227-240.

Comm, C. and Mathaisel, D. (2008) 'Implementing a lean enterprise approach to achieve business excellence', International Journal of Business Excellence, 1: 448-456.

Cooney, R. (2002) 'Is "lean" a universal production system?: Batch production in the automotive industry', International Journal of Operations \& Production Management, 22: 1130-1147.

Cusumano, M.A. (1992) 'Japanese Technology Management: Innovations, Transferability, and the Limitations of "Lean" Production', M.I.T. Sloan School of Management Working Paper written for the MIT Symposium on "Managing Technology: The Role of Asia in the 21st Century," Hong Kong, 2-3 July 1992 available at http://dspace.mit.edu/bitstream/handle/1721.1/2437/SWP-347726970551.pdf? sequence $=1$ [last accessed $15^{\text {th }}$ July 2014].

Dankbaar, B. (1997) 'Lean Construction: Denial, Confirmation or Extension of Sociotechnical Systems Design?', Human Relations, 50: 567-583.

de Souza, LB. and Pidd, M. (2011) 'Exploring the barriers to lean healthcare implementation', Public Money \& Management, 31: 59-68.

Dahlgaard, J.J. and Dahlgaard-Park, S.M. (2006) 'Lean production, six sigma quality, TQM and company culture', TQM Magazine, 18: 263-281.

Eagle, L. and Brennan, R. (2007) 'Are students customers? TQM and marketing perspectives', Quality Assurance in Education, 15: 44-60.

Emiliani, M.L. (2004) 'Improving business school courses by applying lean principles and practices', Quality Assurance in Education, 12: 175-87.

Emiliani, M.L. (2011) 'Lean management failure at HMRC', Management Services , 55(4): 13-15. 
Ferlie, E. and Geraghty, K. (2005) 'Professionals in Public Services Organizations: Implications for Public Sector 'Reforming' In E. Ferlie,L.E. Lynn and C.H. Pollitt, (eds.) The Oxford Handbook of Public Management, Oxford: Oxford University Press.

Fillingham, D. (2007) 'Can lean save lives?', Leadership in Health Services, 20: 231241.

Garrahan, P. and Stewart, P. (1992) The Nissan Enigma: Flexibility at Work in a Local Economy, London: Mansell.

Graham, L. (1995) On the Line at Subaru-Isuzu: The Japanese Model and the American Worker, Ithica NY: Cornell University Press.

Green, S.D. (2002), 'The Human Resource Management Implications of Lean Construction: Critical Perspectives and Conceptual Chasms', Journal of Construction Research, 3: 147-165.

Gruber, T., Fub, S., Voss, R. \& Glaser-Zikuda, M. (2010) 'Examining student satisfaction with higher education services using a new measurement tool', International Journal of Public Sector Management, 23: 105-123.

Guest, D. (1987) 'Human resource management and industrial relations', Journal of Management Studies, 24(5): 503-21.

Hines, P. and Lethbridge, S, (2008) 'New Development: Creating a Lean University', Public Money \& Management, 28: 53 - 6.

Holweg, M. (2007) 'The genealogy of lean production', Journal of Operations Management, 25: 420-437.

Ichniowski, C., Shaw, K. and Prennushi, G. (1997) 'The effects of human resource management practices on productivity: a study of steel finishing lines', American Economic Review, 87: 291-313.

Jorgensen, B \& Emmitt, S (2008) 'Lost in transition: the transfer of lean manufacturing to construction', Engineering, Construction and Architectural Management, 15(4): 383 - 98.

Kehoe, R.R., and Wright, P.M. (2013) 'The Impact of High Performance Human Resource Practices on Employees' Attitudes and Behaviors', Journal of Management, 39: 366-391.

Koch, J.V. (2003) 'TQM: why is its impact in higher education so small?', The TQM Magazine, 15: 325-333.

Kollberg, B., Dahlgaard, J. and Brehmer, P. (2007) 'Measuring lean initiatives in healthcare services: issues and findings', International Journal of Productivity and Performance Management, 56: 7-24.

Krafcik, J. (1988) 'The triumph of the lean production system', Sloan Management Review, 31: 41-52.

Lado, A.A. and Wilson, M.C. (1994) 'Human Resource Systems and Sustained Competitive Advantage: A Competency-Based Perspective', Academy of Management Review, 19: 699-727.

Laureani, A., Antony, J. and Douglas, A. (2010) 'Lean six sigma in a call centre: a case study', International Journal of Productivity and Performance Management, 59(8): $757-768$.

Legge, K. (1995) Human Resource Management: Rhetorics and Realities, Basingstoke, Macmillan.

Lewis, M. (2000) 'Lean production and sustainable competitive advantage', International Journal of Operations \& Production Management, 20: 959-978.

Liker, J. (2004) The Toyota Way, 14 Principles of Management from the World's Greatest Manufacturer, New York: McGraw Hill. 
Lorenz, E. and Valeyre, A. (2005) 'Organisational Innovation, Human Resource Management and Labour Market Structure: A Comparison of the EU-15', The Journal of Industrial Relations, 47: 424-442.

Lynch, R. and Baines, P. (2004) 'Strategy development in UK higher education: towards resource-based competitive advantage', Journal of Higher Education Policy and Management, 26: 171-187.

MacDuffie, J.P. (1995) 'Human Resource Bundles and Manufacturing Performance: Organizational Logic and Flexible Production Systems in the World Auto Industry', Industrial and Labor Relations Review, 48: 197-221.

Martin, S.H., and Arokiam, I. (2007) 'An Investigation into the Application of Lean Techniques within the Education Sector'. Proceedings of the iPED conference, 10-11 Sept, Coventry, UK.

New, S.J. (2007) 'Editorial: Celebrating the enigma: the continuing puzzle of the Toyota Production System', International Journal of Production Research, 45(16): 3545-3554.

Nishii, L.H., Lepak, D.P., and Schneider, B. (2008) 'Employee Attributions About the 'Why' of HR Practices: Their Effects on Employee Attitudes and Behaviors, and Customer Satisfaction', Personnel Psychology, 61: 503-545.

O'Mahony, K, and Garavan, T.N. (2012) 'Implementing a quality management framework in a higher education organisation: A case study', Quality Assurance in Education, 20: 184-200.

Oliver, N. and Wilkinson, B. (1992) The Japanization of British Industry: Developments in the 1990s, Oxford: Basil Blackwell.

Panizzolo, R. (1998) 'Applying the lessons learned from 27 lean manufacturers. The relevance of relationships management', International Journal Production Economics, 55: 223-40.

Perez, C. (2005) Technological Revolutions and Financial Capital: The Dynamics of Bubbles and Golden Ages, Cheltenham: Edward Elgar Publishing.

Pettersen, J. (2009) 'Defining lean production: some conceptual and practical issues', TQM Journal, 21: 127-142.

Piercy, N. and Rich, N. (2009) 'Lean transformation in the pure service environment: the case of the call service centre', International Journal of Operations \& Production Management, 29(1): 54 - 76.

Pil, F.K. and MacDuffie, J.P. (1996) 'The Adoption of High Involvement Work Practices', Industrial Relations, 35: 423-455.

Price J. (2004) ' Lean production at Suzuki and Toyota: a historical perspective', Studies in Political Economy, 45: 66-99.

Quinn, A., Lemay, G., Larsen, P. and Johnson, D.M. (2009) 'Service quality in higher education', Total Quality Management \& Business Excellence, 20: 139-152.

Radnor, Z. and Boaden, R. (2008) 'Editorial: Lean in Public Services-Panacea or Paradox?', Public Money \& Management, 28: 3-7.

Radnor, Z. and Bucci, G. (2007), Evaluation of PaceSetter Lean, Senior Leadership \& Operational Management within HMRC Processing, London, HMRC.

Radnor, Z. and Bucci, G. (2011) Analysis of Lean Implementation in UK Business School and Universities report for the Association of Business Schools, London: ABS.

Radnor, Z. and Osborne, S.P. (2013) 'Lean: A failed theory for public services? ', Public Management Review, 15(2), 265-287.

Radnor, Z., Walley, P., Stephens, A. and Bucci, G. (2006) Evaluation of the Lean 
Approach to Business Management and Its Use in the Public Sector, Edinburgh: Scottish Executive.

Radnor, Z. and Walley, P. (2008) 'Learning to Walk Before We Try to Run: Adapting Lean for the Public Sector', Public Money and Management, 28: 13-20.

Rahbek, E., Pedersen, G. and Huniche, M. (2011) 'Determinants of lean success and failure in the Danish public sector - A negotiated order perspective', International Journal of Public Sector Management, 24(5): 403-420.

Rinehart, J., Huxley, C. and Robertson, D. (1997): Just Another Car Factory? Lean Production and Its Discontents, Ithaca NY: Cornell University Press.

Shah, R. and Ward, P. (2003) 'Lean manufacturing: context, practice bundles, and performance', Journal of Operations Management, 21(2), 129-49.

Shah, R. and Ward, P. (2007) 'Defining and developing measures of lean production', Journal of Operations Management, 25: 785 - 805.

Stewart, P., Richardson, M., Danford, A., Murphy, K., Richardson, T. and Wass, V. (2009) 'We Sell Our Time No More. Workers' Struggles Against Lean Production in the British Car Industry, London: Pluto Press.

Storey, J. (1987) 'Developments in the management of human resources: an interim report', Warwick Papers in International Relations, University of Warwick.

Storey, J. (1992) 'Developments in the Management of Human Resources', Oxford: Blackwell.

Storey, J. (2007) 'What is Strategic HRM' in J. Storey (ed) Human Resource Management: A Critical Text, $3^{\text {rd }}$ Edition, London: Thomson.

Tracey, M. and Flinchbaugh, J. (2006a) 'How Human Resource Departments Can Help Lean Transformation', Target Magazine, 3: 5-10.

Tracey, M. and Flinchbaugh, J. (2006a) 'HR's Role in the Lean Organizational Journey', WorldatWork Journal, 4: 49-58

Voss, R., Gruber, T. and Szmigin, I. (2007) 'Service Quality in Higher Education: The Role of Student Expectations', Journal of Business Research, 60(9): 949-959.

Womack, J.P. and Jones, D.T. (1996) Lean Thinking: Banish Waste and Create Wealth in your Corporation, New York NY: Free Press.

Womack, J.P. and Jones, D.T. (2005) Lean Solutions: How Companies and Customers Can Create Value and Wealth Together, New York NY: Free Press.

Womack, J.P., Jones, D.T. and Roos, D. (1990) The Machine That Changed The World, New York NY:, Rawson Associates.

Wright, P.M., and McMahan, G.C. (1992), 'Theoretical Perspectives for Strategic Human Resource Management', Journal of Management, 18(2), 295-320.

Wright, P.M., McMahan, G.C., and McWilliams, A. (1994) 'Human Resources and Sustained Competitive Advantage: A Resource-Based Perspective', International Journal of Human Resource Management, 5(2), 301-326. 
Table 1 - Case studies summary

\begin{tabular}{|c|c|c|c|c|c|c|c|}
\hline $\begin{array}{c}\text { Case } \\
\text { pseudonym }\end{array}$ & $\begin{array}{c}\text { Scope of } \\
\text { project }\end{array}$ & $\begin{array}{c}\text { Number of } \\
\text { employees } \\
\text { covered }\end{array}$ & $\begin{array}{l}\text { Initiative } \\
\text { introduced }\end{array}$ & $\begin{array}{l}\text { Training } \\
\text { approach }\end{array}$ & Tools and techniques & Facilitation mechanisms & $\begin{array}{l}\text { Involvement of HR } \\
\text { function }\end{array}$ \\
\hline $\begin{array}{c}\text { Old } \\
\text { University }\end{array}$ & $\begin{array}{l}\text { University } \\
\text { wide }\end{array}$ & c. 9000 & 2007 & $\begin{array}{l}5 \text { day Blitz } \\
\text { events based on } \\
\text { individual } \\
\text { projects } \\
\text { facilitated by } \\
\text { internal Change } \\
\text { Consultants }\end{array}$ & $\begin{array}{l}\text { RIEs } \\
\text { Process mapping } \\
\text { Value stream mapping } \\
\text { Nominal grouping } \\
\text { techniques } \\
\text { Competency } \\
\text { frameworks }\end{array}$ & $\begin{array}{l}\text { Dedicated central Lean } \\
\text { Team leading and } \\
\text { running the project. } \\
\text { External consultancy } \\
\text { employed initially. }\end{array}$ & $\begin{array}{l}\text { HR personnel receive } \\
\text { training when Lean } \\
\text { applied to HR } \\
\text { processes such as } \\
\text { payroll and leave } \\
\text { management. No } \\
\text { involvement in } \\
\text { implementation. }\end{array}$ \\
\hline $\begin{array}{c}\text { New } \\
\text { University }\end{array}$ & $\begin{array}{l}\text { School } \\
\text { within a } \\
\text { University }\end{array}$ & $\begin{array}{c}\text { c. } 65 \\
\text { academic } \\
\text { staff }+ \\
\text { support } \\
\text { staff }\end{array}$ & 2009 & $\begin{array}{l}\text { Intensive } \\
\text { courses and } \\
\text { emersion days } \\
\text { based at Lean } \\
\text { Learning } \\
\text { Academy } \\
\text { facilitated by } \\
\text { automotive } \\
\text { leaders. }\end{array}$ & $\begin{array}{l}\text { A3s } \\
\text { Visual management } \\
\text { Value stream mapping } \\
\text { Root cause analysis } \\
\text { Fishbone diagrams }\end{array}$ & $\begin{array}{l}\text { Project led by Dean of } \\
\text { School. Executive Team } \\
\text { oversees projects with } \\
\text { budget allocation, which } \\
\text { is additional to existing } \\
\text { resources (academic and } \\
\text { support staff). External } \\
\text { academic acts as } \\
\text { consultant. }\end{array}$ & $\begin{array}{l}\text { No HR involvement in } \\
\text { implementation or HR } \\
\text { systems affected } \\
\text { although Executive } \\
\text { Team did anticipate HR } \\
\text { involvement if HR } \\
\text { procedures were to } \\
\text { become targets of Lean } \\
\text { initiative. }\end{array}$ \\
\hline
\end{tabular}

